the 1963 study. the new plot is based on an ipative median split, as opposed to the three highest and three lowest items. lor both studies. Si with all-cero GSR, or only one xorable GSR have been eliminated. This prevents the problem of including a cro GSR in the "high-arousal" category. I or hoth studics, the revised plots are slightly less dramatic than the original ones, but the previously obtained significant interactions still hold.)

\title{
The effect of type of redundancy on retention in preschool children ${ }^{1}$
}

\begin{abstract}
DAVID A. CORSINI, University Georgia, Athens, Ga. 30601

The effect of verbal and nonverbal redundancy on the retention of 30 4-year-old children was examined to determine if the type of redundancy, as opposed to redundancy per se, facilitated the retention of this age child. The results demonstrated that the representational abilities of the child determine what type of redundant information will aid retention.
\end{abstract}

Three previous studies (Corsini, $\left.1969 a, b^{2}\right)$ found preschool children's retention of verbally presented information inferior to retention of information presented both verbally and nonverbally. The retention of older (second-grade) children was generally not different for these two ways of presenting information. These results have been discussed in terms of developmental changes in cognitive abilities for representation of information.

According to both Piaget (1947, and cv. Flavell, 1963) and Bruner (1964, 1966), the means by which the child can represent his environment changes with age. Developmentally, the child is first able to represent his environment only on the basis of his own physical movements; subsequently, the child becomes able to represent his environment through the use of imagery: and finally, the child becomes able to represent $h$ is experience symbolically. The primary hypothesis of the previous studies was that retention should be a joint function of the child's ability to represent information and the nature of the information presentcd. Thus, it was predicted that the preschool child, whose dominant means of representation is imagistic, would show better retention when the presented information allowed the use of imagery than when it did not; and additionally, this would not be the case for second-grade children who were capable of symbolic representation.

While the results of the previous studies have generally supported these predictions, the point can be raised that the preschool child's retention of information presented both verbally and nonverbally is superior not because the nonverbal information allows the preschool child to use imagery, but because a verbal-nonverbal message is simply more redundant than the verbal message. The present study asks whether the superior retention of preschool children for a verbal-nonverbal message is a function of simple redundancy (getting the message twice) or the specific type of redundancy (the nonverbal elements allowing the child to use imagery).

\section{GENERAL}

As in previous studies, $S$ was presented a simple instruction concerning the manipulation of familiar objects. The independent variable was the manner in which the instruction was presented. Retention was assessed nonverbally by requesting $S$ to perform the instruction with a set of objects made available after the instruction had been given.

\section{CONDITIONS}

\section{Verbal}

The $\mathrm{S}$ was given instructions only verbally. This assessed his ability to retain an entirely symbolic message.

$$
\text { Verbal-Nonverbal }
$$

The child was given instructions both verbally and nonverbally. If the instruction was, "Put the red car into the blue cup," the E held up a red car as he said "red car" and a blue cup as he said "blue cup." The objects were held up simultaneously with the verbal utterance but did not remain in S's view, i.e., no two objects were simultaneously in view.

\section{Verbal-Twice}

The $S$ was given instructions only verbally, as in the verbal condition, but was given the instruction twice before being asked to perform the instruction. This condition provided the child with redundant information-the instruction given twice-but the redundancy was only verbal.

The main comparison of interest is between the verbal-nonverbal condition and the verbal-twice condition. If the superior performance of preschool children in the verbal-nonverbal conditions of previous studies was a function of simple redundancy of information, then there should be no difference between these two conditions. However, if the young child retains verbally presented information poorly because he is cognitively less able to deal with symbolic information, then he should not profit significantly from receiving the verbal message twice.

\section{SUBJECTS}

Thirty preschool children (mean age $=$ 53.8 months) were obtained from the University of Georgia Laboratory Nursery School and a church-sponsored nursery school near the University of Georgia. There were 15 males and 15 females in the sample. The sample was predominantly white and from middle-class socioeconomic background.

STIMULI
The stimuli about which the to-be-retained instructions were given consisted of toy cars, crayons, cups, and boxes, each represented by three colors-red, yellow, and blue.

INSTRUCTIONS

Three levels of instructions were used in each condition. The levels differed in terms of the amount to be retained: two objects, three objects, and four objects. For example: Put the blue crayon in the red cup; put the blue car and yellow crayon in the red box; and put the yellow car in the blue cup and the red crayon in the yellow box.

\section{DESIGN}

Each $S$ received each of the conditions. The order of conditions was arranged so that $10 \mathrm{Ss}$ received each of the conditions first; 10 Ss received each of the conditions second, and $10 \mathrm{Ss}$ received each of the conditions third. This arrangement allowed for a between-Ss as well as a within-Ss analysis.

\section{SCORING}

Each of the objects used by $S$ was given a score of 1 if they had been mentioned in the instruction. If the pairing of objects was correct, an additional point was given in order to distinguish between partially correct and completely correct performance. For the three instructions given in each condition, the total possible score was 13 .

\section{PROCEDURE}

Each $S$ was asked to identify the objects and the colors used in the instructions. If $S$ was not sure of these, he was replaced. Four Ss were eliminated for this reason. The $S$ was then told he would be asked to do different things with the objects and was given one practice trial with the 
rbjects to demonstrate the general redure.

\section{RESULTS}

When the performance of all Ss in each of the three conditions was considered, the nean scores were: verbal, 6.5 ; verbal-twice,

i; and verbal-nonverbal, 8.3. A repeated asure analysis of variance revealed a ignificant condition effect $[F(2,58)=7.78, p<.001]$. Further comparisons between means revealed retention in the verbal-nonverbal condition to be significantly greater $(p<.01)$ than in the two verbal conditions that did not differ from each other.

Further analyses were performed to determine whether the order in which the different conditions were given had an effect upon performance. These analyses revealed that there was no differential performance in the verbal and the verbal-twice conditions as a function of when they were given (i.e., first, second, or third), but that there was a significant effect on performance in the verbal-nonverbal condition. Performance in the verbal-nonverbal condition was high for those Ss who had it as the first condition (mean $=10.3)$ and decreased so that performance for those Ss who had verbal-nonverbal as the last condition performed no differently than did Ss in the other two conditions. Thus, significantly better retention in the verbal-nonverbal condition was achieved only if this condition was the first or second condition given. Sex of $S$ was found to be of no significance for performance. DISCUSSION

Previous studies by the present author had found the preschool child's retention to be superior when the to-be-remembered information was presented with the support of concrete perceptual cues. It had been proposed that this effect could be understood from the imagistic nature of the preschool child's dominant mode of representation. The present study was designed to assess if this explanation, as opposed to a simple redundancy explanation, was warranted. The present results strongly support the hypothesis that the preschool child's superior retention of a verbal-nonverbal message is best understood from the nature of the child's dominant mode of cognitive representation and is not a function of simple redundancy.

Although the verbal-nonverbal and verbal-twice conditions were constructed to differ in type of redundancy, they also differ in the sequencing of the redundancy. In the verbal-twice condition, the redundant information is presented successively; in the verbal-nonverbal condition, the redundant information is presented simultaneously. It is possible that the different sequencing of the redundant information, and not the type of redundancy, was the critical factor for retention. The effect of sequence could be examined by adding a condition in which the verbal and nonverbal information was presented successively and a condition in which the double verbal information was presented more simultaneously (this could be approximated by an instruction such as "Put the red car, red car in to the blue cup, blue cup"). While it would be interesting to explore the effect of sequence, the conditions necessary to do it, as described above, would probably strike the young child as somewhat peculiar.

While alternate means of providing verbal redundancy could be arranged and the effect of sequence has not been determined, the present procedure fairly adequately demonstrates that simple repetition of information of a symbolic type does not aid a child who has not yet fully mastered the symbolic mode of represention. These results should not be interpreted to mean that the preschool child is completely unable to remember verbally presented information. The ability to represent symbolic information is beginning to develop in the 4-year-old child and improvement of retention might be expected with some additional amount of verbal repetition. However, the results strongly suggest that the retention of information by preschool children will be most efficiently enhanced by nonverbal supports. These results are consistent with, and provide additional support for, Piaget's and Bruner's discussions of cognitive development.

\section{REFERENCES}

BRUNER, J. S. The course of cognitive growth. American Psychologist, 1964, 19, 1-15.

BRUNER, J. S., Olver, R. R., \& Greenfield, P. M., et al. Studies in cognitive growth. New York: Wiley, 1966.

CORSINI, D. A. The effect of nonverbal cues on the retention of kindergarten children. Child Development, 1969a, 40, 599-607.

CORSINI, D. A. Developmental changes in the effect of nonverbal cues on retention. Developmental Psychology, 1969b, 1 , 425-435.

CORSINI, D. A. Developmental changes in the use of different stimulus cues for retention. Unpublished manuscript, University of Georgia, 1969.

FLAVELL, J. H. The developmental psychology of Jean Piaget. New Jersey: Van Nostrand, 1963.

PIAGET, J. The psychology of intelligence. (Originally published 1947) Ames, Iowa: Littlefield, Adams, 1963.

\section{NOTE}

1. This study was supported in part by the Office of General Research and the Research and Development Center in Educational Stimulation, University of Georgia. The help of Wayne Helms is gratefully acknowledged. 